\title{
IDENTIFICAÇÃO DE MICRORGANISMOS ISOLADOS EM FRUTAS, POLPAS E AMBIENTE INDUSTRIAL
}

\author{
RENATA TORREZAN * \\ MIRTHA NELLY UBOLDI EIROA ** \\ LUDWIG PFENNING ***
}

\begin{abstract}
As frutas e seus derivados são em geral alimentos ácidos, sendo contaminados principalmente, por bactérias lácticas, leveduras e fungos filamentosos. Neste trabalho foram isolados e identificados os microrganismos presentes em frutas e polpas de frutas e no ambiente industrial de seu processamento, sendo detectado predomínio de fungos nas amostras analisadas. As bactérias lácticas tiveram maior incidência nas superfícies analisadas.
\end{abstract}

\section{INTRODUÇÃO}

O desenvolvimento microbiano nos alimentos é condicionado por diversos fatores ambientais, como temperatura e umidade relativa, denominados extrínsecos e por fatores intrínsecos, sendo os principais a atividade de água, o pH, o potencial redox e a composição do alimento (4).

CORLETT JR. \& BROWN (1) afirmam que o pH dos alimentos é um dos fatores que determinam 0 crescimento $e$ a sobrevivência de microrganismos durante seu processamento, estocagem e distribuição. Os microrganismos são afetados pela presença do íon $\left[\mathrm{H}^{+}\right]$livre e pela concentração de ácido fraco não dissociado. Os ânions de alguns ácidos fracos (por exemplo ácido acético ou láctico) são metabolizados dentro da célula bacteriana, havendo liberação do íon $\left[\mathrm{H}^{+}\right]$e acidificação da célula em níveis inibitórios. Outros ânions não são metabolizados e portanto não acidificam as células. Certas cepas de microrganismos podem desenvolver

* M.Sc. em Tecnologia de Alimentos, Embrapa Agroindústria de Alimentos, Rio de Janeiro - RJ (e-mail: torrezan@ctaa.embrapa.br).

** D.Sc. em Ciência e Tecnologia de Alimentos, Professora Colaboradora da Faculdade de Engenharia de Alimentos (FEA), Universidade de Campinas (UNICAMP), Campinas, SP.

*** Ph.D em Ciências Naturais, Departamento de Fitopatologia, Universidade Federal de Lavras, MG. 
resistências ao abaixamento de $\mathrm{pH}$ e conseguir, assim, multiplicar-se em condições adversas (14).

As frutas e seus produtos são em geral alimentos ácidos ou que podem ser acidificados para sua melhor conservação. A maior parte da microbiota contaminante das frutas reside na parte externa das frutas, sendo o seu interior praticamente estéril, a menos que haja alguma ruptura de continuidade por lesões em alguma parte da casca. A microbiota que contamina os produtos de frutas é proveniente das condições da matériaprima e da lavagem a qual esta é submetida, além das condições higiênico-sanitárias dos manipuladores, equipamentos e ambiente industrial em geral. $\mathrm{O} \mathrm{pH}$ destes produtos não favorece, em geral, a proliferação de microrganismos, principalmente os patogênicos (11), podendo haver apenas desenvolvimento de microrganismos deteriorantes como bolores, leveduras, bactérias lácticas e outros microrganismos ácido tolerantes como bactérias acéticas, Zymomonas e algumas espécies de Bacillus.

Devido a sua baixa resistência térmica, as leveduras e os bolores raramente estão associados a processos de deterioração de produtos ácidos que sofreram tratamento térmico, como a pasteurização (5). Deve ser lembrada porém, a existência de espécies termo-resistentes de fungos deterioradores.

O objetivo deste trabalho foi 0 isolamento e identificação de bactérias lácticas, leveduras e fungos filamentosos de polpas, frutas e do ambiente industrial de seu processamento para o conhecimento da microbiota potencial de contaminação destes produtos.

\section{MATERIAL E MÉTODOS}

\subsection{MATERIAL}

\subsubsection{Frutas}

O material em estudo foi constituído de amostras de goiaba e morango in natura, polpa de goiaba concentrada $\left(15^{\circ}\right.$ Brix $)$ e polpas de frutas congeladas (morango, morango com sementes, morango adicionado de açúcar e maracujá).

\subsubsection{Ambiente industrial}

Todas as amostras de ar e das superfícies de equipamentos e utensílios foram obtidas em indústria processadora, localizada no estado de São Paulo. 


\subsubsection{Meios de cultura e diluentes para as análises microbiológicas}

PDA (Ágar de batata dextrose), ref. 10130 Merck, adicionado de $2 \mathrm{~mL}$ de solução de antibióticos $(500 \mathrm{mg}$ de cloranfenicol e $500 \mathrm{mg}$ de clorotetraciclina- $\mathrm{HCl}$ em $100 \mathrm{~mL}$ de tampão fosfato $\mathrm{pH} \mathrm{7,2} \mathrm{estéril)} \mathrm{para}$ cada $100 \mathrm{~mL}$ de meio; MRS Ágar (Ágar de Man, Rogosa e Sharpe) ref. 10660 Merck; solução salina peptonada (1,0 litro de água destilada, 8,5 g de $\mathrm{NaCl}, 1,0 \mathrm{~g}$ de Peptona-L37).

\subsubsection{Meios de cultura utilizados para seleção, identificação e manutenção das cepas isoladas}

PDA; MRS Ágar; Ágar Rogosa, ref. 5413 Merck; OSA (Ágar Soro de Laranja), ref. 0521, Difco Laboratories; MA (Ágar Malte), ref. 0024-01-1, Difco Laboratories; (MEA) Ágar Extrato de Malte, ref. 5398, Merck; meio de Wickerham $(0,67 \mathrm{~g}$ de Bacto Yeast Nitrogen Base, ref. 0392-15, Difco Laboratories e $1 \mathrm{~g}$ de glicose PA Merck, para $100 \mathrm{~mL}$ de $\mathrm{H}_{2} \mathrm{O}$ destilada) e meio para Teste de Nitrato $(1,17 \mathrm{~g}$ de Bacto Yeast Carbon Base, ref. 039115-0, Difco Laboratories, e $0,078 \mathrm{~g}$ de $\mathrm{KNO}_{3}$ para $100 \mathrm{~mL} \mathrm{H} \mathrm{H}_{2} \mathrm{O}$ destilada). Os meios OA (Ágar de Aveia), PCA (Ágar de Batata e Cenoura) e CYA (Ágar Extrato de Levedura de Czapek) foram preparados e as suas formulações encontram-se descritas em TORREZAN (13).

\subsection{MÉTODO EXPERIMENTAL}

As amostras do ambiente industrial foram coletadas e identificadas de acordo com a sua localização. A linha de produção conta com duas salas diferentes. Para facilitar a referência destes ambientes designou-se, aleatoriamente, estas salas como 1 e 2 . $\mathrm{Na}$ sala 1 são realizadas a recepção, lavagem, seleção e cozimento das matérias-primas utilizadas. $\mathrm{Na}$ sala 2 ocorrem as operações de preparo, desintegração, pasteurização e envasamento.

Após avaliação visual da linha de produção foram escolhidos cinco pontos diferentes para coleta de amostras do ar, a saber: sala 1, próximo à porta; sala 2, próximo ao preparo, ao exaustor, ao desintegrador e ao envase. Nestes locais foram colocadas placas de Petri com os seguintes meios de cultura: PDA, OSA, Rogosa e MRS Ágar. O primeiro meio foi utilizado visando $o$ isolamento de fungos filamentosos e leveduras, e os demais, de bactérias lácticas. Estas placas foram deixadas por cerca de 20 minutos abertas, expondo o meio de cultura ao ambiente industrial, sendo a seguir incubadas a $25^{\circ} \mathrm{C}$ por 5 dias, no caso das placas de PDA e a $30^{\circ} \mathrm{C}$ por 72 horas no caso das placas de OSA, Rogosa e MRS. As placas contendo os meios (OSA, Rogosa e MRS) para isolamento das bactérias lácticas foram incubadas em atmosfera microaerófila. Após incubação foram isoladas as 
colônias que apresentaram diferentes morfologias, as quais foram transferidas para tubos inclinados com o respectivo meio de cultura. A indústria foi visitada no período da tarde e a temperatura ambiente era de $22{ }^{\circ} \mathrm{C}$ em média.

A contaminação superficial foi avaliada pela amostragem de cinco superfícies diferentes: mesa de madeira (utilizada na limpeza e seleção das matérias-primas "in natura"), mesa de inox (utilizada na mistura de frutas e açúcar), balde plástico (no qual estavam acondicionadas as frutas congeladas destinadas ao reprocessamento), desintegrador (entrada e saída do desintegrador). Estas superfícies foram amostradas mediante esfregaço com zaragatoas estéreis umedecidas com solução salina peptonada e que foram imediatamente transferidas para tubos com $5 \mathrm{~mL}$ de solução salina peptonada. Estes tubos foram agitados, retirando-se uma alíquota de $0,1 \mathrm{~mL}$ para o plaqueamento por espalhamento em superfície nos meios de cultura mencionados. As placas foram incubadas nas mesmas condições anteriormente citadas. Após o período de incubação foram isoladas as colônias que apresentaram diferentes morfologias, as quais foram transferidas para tubos com meio inclinado.

No caso específico das frutas que estavam sendo processadas foram retiradas amostras, assepticamente, para contagem (15) e isolamento de microrganismos.

Uma porção de polpa de goiaba proveniente de outra indústria processadora de doces de goiaba, localizada na região de Campinas/SP, foi exposta ao ambiente industrial, por cerca de 10 dias até a sua deterioração ser evidente a olho nu. Os microrganismos presentes foram igualmente isolados e transferidos para tubos inclinados, como já mencionado.

Todas as culturas isoladas foram separadas por origem, devidamente codificadas e adequadamente purificadas.

As culturas de leveduras foram inoculadas por estrias em superfície de placas de Petri com meio de Ágar Malte e incubadas a $25^{\circ} \mathrm{C}$ por 5 dias. Após este período, as placas foram observadas sob microscópio esteroscópico (BAUSCH \& LOMB) e as colônias que se diferenciaram pela sua morfologia foram isoladas em tubos contendo o mesmo meio inclinado. Foram realizados esfregaços em lâminas de cada uma das colônias isoladas para observação em microscópio (CARL ZEISS, com contraste de fase).

As culturas de leveduras foram identificadas pelo sistema API 20 C AUX (Bio Mérieux S.A.) para identificação rápida de leveduras, sendo os resultados obtidos complementados com provas de assimilação de nitrato (6), crescimento a $37^{\circ} \mathrm{C}(6)$ e observação microscópica. 
As culturas de bactérias foram isoladas por estrias em superfície em placas de Petri com o meio Ágar MRS e incubadas a $30{ }^{\circ} \mathrm{C}$ por 72 horas em atmosfera microerófila. Cada colônia característica isolada foi repicada para tubo com Ágar MRS inclinado e incubada a $30^{\circ} \mathrm{C}$ por 72 horas. Foram realizados esfregaços em lâminas de cada uma das colônias isoladas para observação em microscópio. Após o período de incubação foi realizada a coloração de Gram (10). A observação das lâminas foi feita em microscópio (Spencer). Como a coloração de Gram não é conclusiva foi realizado, também, o teste da catalase (12). Estas culturas foram devidamente identificadas com kit para identificação rápida de Lactobacillus API 50 CHL (Bio Mérieux).

As culturas de fungos filamentosos foram inoculadas na superfície de placas com Ágar Extrato de Malte para purificação e incubadas a $25^{\circ} \mathrm{C}$ por 5 dias. Todas as colônias visualmente diferentes foram selecionadas e purificadas em tubos com Ágar Extrato de Malte e incubadas a $25^{\circ} \mathrm{C}$ por 5 dias. Após o período de incubação foram feitas lâminas para observação microscópica e nova seleção para separar os fungos filamentosos, por gênero, para o seu cultivo nos meios apropriados para a sua identificação. Os fungos filamentosos do gênero Penicillium foram cultivados em meio MEA e CYA. As placas foram inoculadas em três pontos equidistantes e incubadas a $28^{\circ} \mathrm{C}$ por 7 dias. Após o período de incubação foram feitas as medições das colônias, observações das mesmas na lupa e lâminas para as medições, ao microscópio, dos conídeos, fiálides, vesículas e métulas, de acordo com cada caso. A identificação das espécies foi feita com o auxílio das chaves propostas por PITT (9). As espécies de fungos filamentosos dos gêneros Fusarium, Cladosporium, Scopulariopsis e de Coelomycetes e Ascomycetes foram cultivados nos meios AO, MA, PCA, CYA e MEA, respectivamente. A inoculação foi feita mediante estria com agulha na parte central das placas. As placas foram deixadas no laboratório em temperatura ambiente por cerca de 7 dias ou mais de acordo com o desenvolvimento das culturas. Em duas culturas de Ascomycetes foi possível a visualização dos ascos. Foram medidas a largura e o comprimento dos ascosporos com auxílio de ocular micrométrica, sendo utilizada a chave de classificação proposta por GRAHAM \& LUTTRELL (3).

As espécies fúngicas do gênero Fusarium foram identificados com auxílio da chave proposta por NELSON et al (8) e as espécies do gênero Cladosporium pela chave proposta por DOMSCH et al (2). Dentre as colônias avaliadas havia uma de gênero Scopulariopsis, cuja identificação ocorreu com auxílio da chave proposta por MORTON \& SMITH (7).

\section{RESULTADOS E DISCUSSÃO}

No caso específico da amostragem da saída do desintegrador nenhum microrganismo foi isolado, pois esta região é aquecida e as bactérias 
lácticas e fungos, salvo raras exceções, apresentam baixa resistência térmica. De modo geral, obteve-se microbiota variada dos três grupos de microrganismos em todas as amostragens. Em alguns casos foi necessário descartar as placas, pois o crescimento intenso e diversificado de várias espécies de microrganismos impossibilitou o seu isolamento. Com base nos dados apresentados nas Tabelas 1, 2 e 3 e nos diferentes nichos de amostragem observou-se que, as leveduras estão amplamente distribuídas em todas as amostras examinadas. Foram isoladas ao todo, cerca de 135 cepas de leveduras num total de 240 cepas isoladas das diferentes espécies de microrganismos. Foram isoladas, inicialmente, 55 cepas de fungos filamentosos e 42 de bactérias lácticas. Houve predomínio de fungos filamentosos e leveduras no ambiente industrial e no isolamento a partir das frutas e seus produtos. As bactérias lácticas foram isoladas com maior freqüência nas amostragens das superfícies dos equipamentos, mesas de madeira (utilizadas na manipulação da matéria-prima "in natura") e mesa de inox (utilizada para misturas de frutas higienizadas e açúcar). Nas amostras de polpa de goiaba deteriorada por exposição ao ambiente industrial todos os microrganismos foram isolados em meio de cultura PDA, sendo 07 de fungos filamentosos, 01 de bactéria láctica e 01 de levedura.

Em relação aos meios de cultura utilizados observou-se que o meio de cultura PDA foi bastante eficiente para 0 isolamento dos fungos filamentosos e leveduras. Considerando-se que os meios utilizados para o crescimento de bactérias lácticas são muito ricos e não seletivos pode-se notar que os fungos apresentaram crescimento também neste meio (principalmente as leveduras). O Ágar Rogosa foi o que menos possibilitou 0 isolamento dos microrganismos alvos. Os meios Ágar MRS e OSA apresentaram comportamento semelhante em relação ao número de cepas isoladas.

\section{TABELA 1 - NÚMERO DE CEPAS DE BACTÉRIAS LÁCTICAS, FUNGOS FILAMENTOSOS E LEVEDURAS ISOLADAS NO AMBIENTE INDUSTRIAL EM DIFERENTES MEIOS DE CULTURA}

\begin{tabular}{cccc}
\hline Meio & $\begin{array}{c}\text { Bactérias } \\
\text { Lácticas }\end{array}$ & Leveduras & $\begin{array}{c}\text { Fungos } \\
\text { Filamentosos }\end{array}$ \\
\hline PDA & 5 & 17 & 34 \\
OSA & 1 & 4 & - \\
MRS & 2 & 6 & 1 \\
ROGOSA & 1 & 1 & - \\
\hline TOTAL & 9 & 28 & 35 \\
\hline
\end{tabular}




\section{TABELA 2 - NÚMERO DE CEPAS DE BACTÉRIAS LÁCTICAS, FUNGOS FILAMENTOSOS E LEVEDURAS ISOLADAS EM SUPERFÍCIES DE EQUIPAMENTOS E UTENSÍLIOS INDUSTRIAIS COM DIFERENTES MEIOS DE CULTURA}

\begin{tabular}{cccc}
\hline Meio & $\begin{array}{c}\text { Bactérias } \\
\text { Lácticas }\end{array}$ & Leveduras & $\begin{array}{c}\text { Fungos } \\
\text { Filamentosos }\end{array}$ \\
\hline PDA & 1 & 11 & - \\
OSA & 3 & 12 & - \\
MRS & 6 & 5 & - \\
ROGOSA & 12 & 2 & - \\
\hline TOTAL & 22 & 30 & - \\
\hline
\end{tabular}

\section{TABELA 3 - NÚMERO DE CEPAS DE BACTÉRIAS LÁCTICAS, FUNGOS FILAMENTOSOS E LEVEDURAS ISOLADAS NAS AMOSTRAS DE FRUTAS EM DIFERENTES MEIOS DE CULTURA}

\begin{tabular}{cccc}
\hline Meio & $\begin{array}{c}\text { Bactérias } \\
\text { Lácticas }\end{array}$ & Leveduras & $\begin{array}{c}\text { Fungos } \\
\text { Filamentosos }\end{array}$ \\
\hline PDA & - & 31 & 9 \\
OSA & 7 & 22 & 3 \\
MRS & 3 & 21 & 1 \\
ROGOSA & 1 & 2 & - \\
\hline TOTAL & 11 & 76 & 13 \\
\hline
\end{tabular}

A Tabela 4 apresenta os dados das contagens de microrganismos em frutas e seus produtos. Na amostra de goiaba "in natura" verificou-se contagem menor do que a habitual para produtos "in natura". Tal fato pode ser decorrente da utilização da variedade de mesa, plantada, colhida e transportada com maior zelo do que as normalmente destinadas ao processamento industrial. As polpas de frutas apresentaram contagens entre $10^{2}$ e $10^{3} \mathrm{UFC} / \mathrm{g}$, com exceção da polpa de maracujá $\left(10^{4} \mathrm{UFC} / \mathrm{g}\right)$.

As Tabelas 5, 6 e 7 apresentam uma lista dos gêneros e espécies identificados das cepas de bactérias, leveduras e fungos filamentosos. Não foram mencionadas as cepas iguais em gênero e espécie para o mesmo local de amostragem. 


\section{TABELA 4 - CONTAGEM DE FUNGOS FILAMENTOSOS, LEVEDURAS E BACTÉRIAS LÁCTICAS EM FRUTAS E SEUS PRODUTOS}

\begin{tabular}{cccc}
\hline \multirow{2}{*}{ Amostra } & $\begin{array}{c}\text { J iungos filamentosos e } \\
\text { Leveduras (UFC/g)* }\end{array}$ & & \\
\cline { 3 - 4 } & & & E actérias Lácticas (UFC/g)* \\
\cline { 3 - 4 } $\begin{array}{c}\text { congeladas } \\
\text { Polpa de morango e sementes }\end{array}$ & $4,2.10^{3}$ & $3,9.10^{3}$ & $3,7.10^{3}$ \\
Polpa de morango congelada & & & $1,7.10^{3}$ \\
Polpa de morango congelada & & & \\
adicionada de açúcar & $4,0.10^{2}$ & $8,0.10^{2}$ & \\
Polpa de maracujá & & & $6,0.10^{4}$ \\
Morango "in natura" & $3,3.10^{4}$ & $2,9.10^{4}$ & $1,4.10^{6}$ \\
Goiaba "in natura" & $1,0.10^{6}$ & $1,1.10^{6}$ & \\
\hline
\end{tabular}

* UFC/g = unidades formadoras de colônias por grama.

\section{TABELA 5 - ESPÉCIES DE BACTÉRIAS LÁCTICAS ISOLADAS DO AMBIENTE INDUSTRIAL, DE FRUTAS E SEUS PRODUTOS}

\begin{tabular}{|c|c|}
\hline $\begin{array}{l}\text { I OCAL DE } \\
\text { / MOSTRAGEM }\end{array}$ & l )ENTIFICAÇÃO \\
\hline Balde plástico & Leuconostoc mesenteroides ssp cremoris \\
\hline Balde plástico & Lactobacillus plantarum \\
\hline Mesa de inox & Lactobacillus plantarum \\
\hline Mesa de inox & $\begin{array}{l}\text { Leuconostoc mesenteroides ssp mesenteroides/ } \\
\text { dextranicum }\end{array}$ \\
\hline Mesa de madeira & $\begin{array}{l}\text { Leuconostoc mesenteroides ssp mesenteroides/ } \\
\text { dextranicum }\end{array}$ \\
\hline Desintegrador & $\begin{array}{l}\text { Leuconostoc mesenteroides ssp mesenteroides/ } \\
\text { dextranicum }\end{array}$ \\
\hline Sala 1 (próximo à porta) & Lactobacillus plantarum \\
\hline $\begin{array}{l}\text { Polpa morango e sementes } \\
\text { congeladas }\end{array}$ & Lactobacillus plantarum \\
\hline Polpa morango congelado & Leuconostoc mesenteroides ssp cremoris \\
\hline Polpa de maracujá & Lactobacillus brevis \\
\hline Maracujá "in natura" & Leuconostoc citreum \\
\hline
\end{tabular}


A Tabela 5 demonstra a ocorrência próxima entre as bactérias lácticas dos gêneros Leuconostoc e Lactobacillus, com respectivamente 6 e 5 cepas. Já para as leveduras a maior ocorrência, conforme apresentado na Tabela 6, foi do gênero Candida com 8 cepas. De acordo com a Tabela 7, entre os fungos filamentosos a maior ocorrência foi do gênero Penicillium (9 cepas), seguido pelo Ascomycetes (6 cepas). No caso específico dos Ascomycetes, estas cepas seriam supostamente Ascomycetes, pois não foi possível visualizar os ascos na observação ao microscópio. Para a identificação das culturas de Ascomycetes existe a possibilidade do seu cultivo em meio de cultura $\mathrm{OA}$ com pedaços de folha de bananeira, por cerca de 6 meses o que fugiria aos objetivos deste trabalho, entretanto, em duas destas culturas foi possível a visualização dos ascos, o que permitiu a sua identificação.

\section{TABELA 6 - GÊNERO E ESPÉCIES DE LEVEDURAS ISOLADAS NO AMBIENTE INDUSTRIAL, EM FRUTAS E SEUS PRODUTOS}

\begin{tabular}{ll}
\hline I OCAL DE AMOSTRAGEM & l )ENTIFICAÇÃO \\
\hline Sala 2 (próximo ao enchimento) & Rhodotorula sp \\
Sala 2 (próximo ao preparo) & Candida magnoliae \\
Sala 2 (próximo ao desintegrador) & Rhodotorula sp \\
Sala 2 (próximo ao desintegrador) & Rhodotorula glutinis \\
Desintegrador & Rhodotorula sp \\
Desintegrador & Kloeckera apiculata \\
Desintegrador & Torulopsis candida \\
Desintegrador & Candida magnoliae \\
Mesa de inox & Hansenula sp \\
Polpa de morango congelada & Candida pelicullosa \\
adicionada de açúcar & \\
Polpa de maracujá & Candida inconspicua \\
Polpa de maracujá & Kloeckera apiculata \\
Polpa de maracujá & Trichosporon pullulans \\
Maracujá “in natura" & Torulopsis magnoliae \\
Maracujá "in natura" & "Yeast like fungi” (levedura com \\
Morango "in natura" & micélio verdadeiro) \\
Morango "in natura" & Candida magnoliae \\
\hline
\end{tabular}




\section{TABELA 7 - GÊNEROS E ESPÉCIES DE FUNGOS FILAMENTOSOS ISOLADOS NO AMBIENTE INDUSTRIAL, EM FRUTAS E SEUS PRODUTOS}

\begin{tabular}{ll}
\hline I OCAL DE AMOSTRAGEM & I JENTIFICAÇÃO \\
\hline Sala 2 (próximo ao exaustor) & Penicillium glabrum \\
Sala 2 (próximo ao exaustor) & Ascomycetes \\
Sala 2 (próximo ao desintegrador) & Penicillium variabile \\
Sala 2 (próximo ao desintegrador) & Penicillium crustosum \\
Sala 2 (próximo ao desintegrador) & Coelomycetes \\
Sala 2 (próximo ao enchimento) & Ascomycetes \\
Sala 2 (próximo ao enchimento) & Leptosphaerulina australis \\
Sala 2 (próximo ao enchimento) & Penicillium viridicatum \\
Sala 2 (próximo ao enchimento) & Coelomycetes \\
Sala 2 (próximo ao enchimento) & Penicillium glabrum \\
Sala 2 (próximo ao preparo) & Penicillium glabrum \\
Sala 2 (próximo ao preparo) & Leptosphaerulina australis \\
Sala 2 (próximo ao preparo) & Ascomycetes \\
Polpa deteriorada de goiaba & Penicillium crustosum \\
Polpa deteriorada de goiaba & Scopulariopsis sphaerospora \\
Polpa deteriorada de goiaba & Penicillium solitum \\
Polpa deteriorada de goiaba & Cladosporium sp \\
Polpa deteriorada de goiaba & Coelomycetes \\
Polpa de morango com açúcar congelada & Ascomycetes \\
Maracujá "in natura" & Fusarium verticillioides ou F. \\
Maracujá "in natura" & moniliforme \\
Maracujá "in natura" & Fusarium subglutinans \\
Goiaba "in natura" & Cladosporium sp \\
Goiaba "in natura" & Penicillium solitum \\
\hline & \\
&
\end{tabular}

\section{CONCLUSÃO}

O meio de cultura PDA mostrou-se eficiente para o isolamento de fungos filamentosos e leveduras. Os meios de cultura Ágar MRS e OSA apresentaram comportamento semelhante no isolamento de bactérias lácticas, possibilitando também, o isolamento de fungos filamentosos e leveduras. 
As frutas analisadas apresentaram contagem da carga microbiana entre $10^{3}$ a $10^{6}$. As polpas de frutas apresentaram contagens entre $10^{2}$ a $10^{4}$, indicando que o processamento das frutas pode contribuir para a redução da carga microbiana.

Pelo número de cepas isoladas observou-se que houve predomínio de leveduras e fungos filamentosos nas amostras do ambiente industrial e de frutas e seus produtos examinados.

As bactérias lácticas tiveram maior incidência nas superfícies dos equipamentos, mesas de madeira e de inox.

Entre as cepas identificadas a maior ocorrência de leveduras foi do gênero Candida e nos fungos filamentosos de Penicillium. No caso das bactérias lácticas os gêneros Leuconostoc e Lactobacillus ocorreram praticamente em populações equivalentes.

\section{Abstract}

Fruits and fruit products are in general acid foods, being mainly contaminated by lactic acid bacterias, yeasts and filamentous fungi. In the present work, microorganisms present in fruits, fruit pulp and industrial environment were isolated and identified, being detected a prevalence of fungi in the samples assayed. The acid lactic bacterias were more incident at the surfaces analyzed.

\section{REFERÊNCIAS BIBLIOGRÁFICAS}

1 CORLETT Jr., P. A., BROWN, M. H. pH and acidity. In: INTERNATIONAL COMMISSION ON MICROBIOLOGICAL SPECIFICATIONS FOR FOODS. Microbial ecology of foods: factors affecting life and death of microrganisms. New York : Academic Press, 1980. v. 1, p. 92-111.

2 DOMSCH, K. H., GAMS, W., ANDERSON, T.H. Compendium of soil fungi. Verlag : IHW, 1993. p. 201-210.

3 GRAHAM, J. H., LUTTRELL, E. S. Species of Leptosphaerulina on forage plants. Phytopathology, v. 51, p. 680-693, Out. 1961.

4 LEITÃO, M. F. de F. Atividade de água e transformações microbiológicas de deterioração. In: SEMINÁRIO SOBRE ATIVIDADE DE ÁGUA EM ALIMENTOS, 1., Campinas, 1987. Resumos.... Campinas : Instituto de Tecnologia de Alimentos, 1987. p. $1-12$. 
5 LEITÃO, M. F. de F. Microbiologia de sucos, polpas e produtos ácidos. In: SOLER, M. P. et al. Industrialização de frutas. Campinas : Instituto de Tecnologia de Alimentos, 1991. p. 33-52. (Manual Técnico, $n^{\circ} 8$ ).

6 LODDER, J. The yeasts: a taxonomic study. 2.ed. Amsterdam : North-Holland, 1971. 1385 p.

7 MORTON, F.J., SMITH, G. The genera Scopulariopsis Bainier Microascus Zukal and Doratomyces Corda. Mycologycal Papers, Surrey, v. 20, n. 86, p. 17-20, 1963.

8 NELSON, P. E., TOUSSOUN, T. A., MARASAS, W. F. O. Fusarium species: an illustrated manual for identification. Pennsylvania : State University Press, 1983. p. 135-138.

9 PITT, J. I. A laboratory guide to common Penicillum species. Sydney : Commonwealth Scientific and Industrial Research Organization, Division of Food Processing, 1988. p. 6-27, 52-57, 104-163.

10 RIBEIRO, M. C., SOARES, M. M. S. R. Microbiologia prática: roteiro e manual de bactérias e fungos. São Paulo : Atheneu, 1993. $112 \mathrm{p}$.

11 SIQUEIRA, R. S. de, BORGES, M. de F. Microbiologia de frutas e produtos derivados. In: TORREZAN, R. (Coord.). Curso de processamento de frutas. Rio de Janeiro : EMBRAPA/CTAA, 1997. p. 2-13.

12 SKERMAN, V. B. D. Abstracts of microbiological methods. New York : John Wiley, 1969. $883 \mathrm{p}$.

13 TORREZAN, R. Preservação de polpa de goiaba por métodos combinados. Campinas, 1996. 211 p. Dissertação (Mestrado), Tecnologia de Alimentos - Faculdade de Engenharia de Alimentos, Universidade Estadual de Campinas.

14 UBOLDI EIROA, M. N. Microbiologia de frutas e hortaliças desidratadas. In: AGUIRRE, J. M., GASPARINO FILHO, J. (coord.). Desidratação de frutas e hortaliças. Campinas : Instituto de Tecnologia de Alimentos, 1996. p. 6.1-6.26.

15 VANDERZANT, C., SPLITTSTOESSER, D. F. (ed.). Compendium of methods for the microbiological examination of foods. 3.ed. Washington : American Public Association, 1992. 1219 p. 